\title{
Intergenerational Perceptions of Household Wellbeing in India's Western and Eastern Ghats
}

\begin{abstract}
India is home to the largest number of people living in poverty in the world. To inform poverty alleviation strategies, we sought local insights on wellbeing trajectories from three generations of respondents in three communities in the Western and Eastern Ghats. An integrated thematic analysis was carried out using qualitative information from focus group discussions (FGDs) and a survey instrument. Overall, we found most households had a positive perspective regarding their wellbeing over time; when divided into research locations, the Odisha site (Jeypore) was the most optimistic, the Kerala site (Wayanad) had no consensus position, and the Tamil Nadu site (Kolli Hills) was most pessimistic. Scheduled tribe (ST) and non-ST households were similar in their wellbeing perceptions despite the ongoing social and economic marginalization of ST households. Common negative events experienced were health (death or alcoholism) and climate disasters (drought or flooding), and common positive events were asset inheritance or government schemes. An important insight was changing importance of events between generations: elder generations valued labour migration, interim generations valued asset inheritance, and the current generation valued government schemes. We conclude that significant events play a major role in wellbeing perceptions among these communities, and understanding the evolving forms of significant events between generations can provide insights towards designing effective poverty alleviation strategies for the future.
\end{abstract}

\section{Keywords}

Wellbeing; intergenerational; trajectory; India; poverty; significant events 


\section{Introduction}

Statistics on global development indicate that the greatest number of the global poor is currently concentrated in highly populated, middle-income countries (Sumner, 2012). In India, despite economic growth rates of nearly 8 per cent since 1990 and a decrease in poverty levels from 40 per cent in 1990 to 13.5 per cent in 2015 (World Bank, 2015), 231 million people remain below the global poverty line and 191 million people are undernourished across the country (FAO, IFAD, \& WFP, 2014). While poverty persists across all regions, it is most evident within the rural areas, where 30 per cent of people are below the national poverty line (Aubron, Lehoux, \& Lucas, 2015; Government of India, 2013).

While the states in southern India typically have lower poverty levels than other parts of the country (Suryanarayana, Agrawal, \& Prabhu, 2011), the communities living within the Western and Eastern Ghat regions ${ }^{1}$ of the Deccan plateau are anomalies to this trend (Government of India, 2016). Several factors contribute to this situation. First, most of these communities are far from major transportation corridors and reliant on marginal agricultural land (Bawa, Joseph, \& Setty, 2007). Second, over 60 per cent of economic activity in rural areas across India is taking place in the agriculture sector, where market volatility, changing climatic conditions, lower profit margins and global competition in the supply chain have led to greater uncertainty (Jacoby, 2016). Further, conversion of wild land to agriculture has depleted the biodiversity resources and natural functioning of ecosystems, leading to decreased food security for local communities (Fisher \& Christopher, 2007). Socially, rural areas are highly populated by

\footnotetext{
${ }^{1}$ The Western Ghats are a continuous mountain range, approximately 160,000 square kilometres in area, that traces the western coast of India (Kadur \& Bawa, 2005), while the Eastern Ghats are a discontinuous mountain range, approximately 75,000 square kilometres in area, that traces the eastern coast of the Bay of Bengal (Reddy, Jha, \& Dadhwal, 2014).
} 
the socially disadvantaged Scheduled Caste (SC) and Scheduled Tribe (ST) communities, who make up only 28 per cent of India's population but account for 43 per cent of those below the poverty line (Government of India, 2013; World Bank, 2016).

Households in these communities in these regions are often slower in wellbeing advance - defined as the positive, holistic and personal qualities associated with development (White, 2010). These populations are also susceptible to intergenerational transmitted poverty traps self-reinforcing mechanisms that cause poverty to persist from one generation to another (Dutta, 2012; Imai, Gaiha, \& Thapa, 2015). Such conditions often lead to a sense of helplessness among entire households and communities (Bird, 2010; Moore, 2001). As such, understanding the actual and perceived state of wellbeing in these communities over time is important for the design of appropriate strategies that promote ascent out of poverty (Krishna, 2006; Moore, 2001).

Literature on intergenerational poverty has identified several important determining factors that may promote or deplete household wellbeing. Such factors include: migration patterns, which can provide external benefit and assistance in terms of seasonal income and remittances (de Brauw, Mueller, \& Woldehanna, 2013; Deshingkar, 2010); significant events such as health, which include an array of occurrences from birth to sickness and death (Alam \& Mahal, 2014; Mazumdar, Mazumdar, Kanjilal, \& Singh, 2014); climatic conditions, such as flooding or drought that may destroy crops (Kreft, Eckstein, Junghans, Kerestan, \& Hagen, 2015; Mazumdar et al., 2014); social entitlement, such as caste, ethnicity, or gender, which create limiting factors to upward mobility (Dillon \& Quiñones, 2010; Haseena, 2015; Meagher, 2010); and the presence or absence of social safety nets, such as government welfare schemes (Moore, 2001; Narayan, Sen, \& Hull, 2010). 
Another important consideration in understanding wellbeing is the interpretation of development. Quantitative measures of development, such as income or consumption, are common metrics to understand the wellbeing of households (Barrett \& Carter, 2013). However, qualitative techniques that measure wellbeing often provide a more nuanced and contextual understanding of development (Novotný, Kubelková, \& Joseph, 2013; Smith- Lovin, 1987; Weber, 2009). We take a qualitative, intergenerational approach in this study to seek insights into the perspectives of household wellbeing change over time (Krishna, 2004; Narayan \& Petesch, 2002), as few studies of this nature exist in these Ghat communities.

The motivation for this paper is to inform poverty alleviation strategies among policy makers in India that align with the needs and expectations of local communities in the Western and Eastern Ghats. Understanding the root causes and dynamics of poverty in India over time is valuable to inform government policy development that promotes ascent out of poverty. While there is indication that poverty reduction is occurring even within rural and remote populations (Government of India, 2013), most research suggests that the current and future state of many of these rural households is not positive, especially among the ST communities (Aubron et al., 2015; Kirubakaran, 2013; Sahoo, 2011).

Our objective is to capture in-depth, qualitative knowledge of wellbeing change over time through an integrated assessment of intergenerational wellbeing trajectories among three marginalized communities. We pose the question: do household representatives from three household generations believe their wellbeing is improving, remaining constant or decreasing over time - and what are the major contributing factors to this increase or decrease? Specifically, we seek greater understanding of their perceived wellbeing changes over time, significant events that have impacted their households, and expectations of the future. 
The paper will be structured in the following manner: Section 2 summarizes the research methodology employed; Section 3 contains the results describing perceived trajectories of wellbeing and shocks, distinguishing between research sites, land ownership and ST membership; Section 4 provides a discussion of results and Section 5 presents our conclusions and areas of future research.

\section{Methodology}

\subsection{Research Location}

The research was conducted in three different states within the Western and Eastern Ghats: Jeypore, Odisha (J); Kolli Hills, Tamil Nadu (K); and Wayanad, Kerala (W) (Figure 1 and Appendix Table 1). The site selection criteria were based upon a similar cross-site physical and human geographic profile and included: a high degree of agrobiodiversity (Jackson, Pascual, \& Hodgkin, 2007), a high percentage of the local population identifying as ST, low levels of development, located in remote regions and representative of differing economic development.

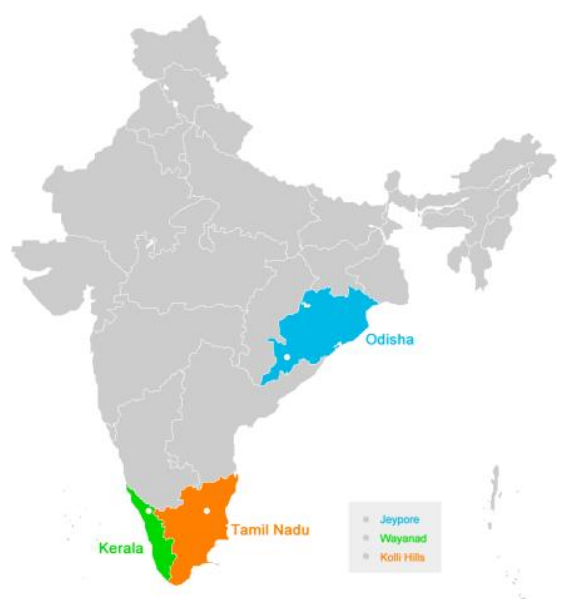

Figure 1. Location of the three research sites in this study: Jeypore (Odisha), Kolli Hills (Tamil Nadu) and Wayanad (Kerala). 


\subsection{Data Collection}

We employed an integrated methodological approach for the primary datasets used in this study. The primary source of data was qualitative focus group discussions (FGDs), informed and complemented by specific questions from a survey instrument. Introductory FGDs were conducted to gauge public awareness and understanding of major issues of concern. A recall approach was used to obtain longitudinal information from previous time periods. ${ }^{2}$ Households selected for participation in the survey instrument were randomly selected from among households within the Block panchayats, ${ }^{3}$ based upon information provided by local partners and government administrative data. A sample size of 300 households in in each research site for totaled a pooled sample of 896 households (Ryan, 2013). ${ }^{4}$

Respondents were asked ${ }^{5}$ to select their wellbeing from five categories, ranging from low (one) to high (five) that reflected the wellbeing in the decade in which the respondent was between 30-40 years. Respondents were also asked to identify the primary major events that have positively and negatively affected their economic wellbeing. Based upon a local historical knowledge of significant events and informed by insights from the preliminary FGDs, respondents were asked to select their experience from nine categories of events: natural disasters, livestock ownership change, land ownership change, change in crop production (new

\footnotetext{
${ }^{2}$ Understanding how individuals, households and communities escape from poverty requires information from several time periods. A recall approach is an effective means to collect historical information in the absence of longitudinal data. A limitation of this approach is degradation of memory, or recall bias, which has been found to impact the accuracy of responses from participants (de Nicola \& Gine, 2012; Kjellsson, Clarke, \& Gerdtham, 2014). However, we mitigated this bias using cross-validation techniques, such as anchoring questions to important events that occurred during the requested time period, complementary community FGDs and validation from other sources of data.

${ }^{3}$ Village.

${ }^{4}$ Four surveys were incomplete in the Kolli Hills research location, resulting in only 296 surveys.

${ }^{5}$ Surveys were written and conducted via interpreter in the local language of each location: Oriya (Odisha), Malayalam (Kerala) and Tamil (Tamil Nadu).
} 
varieties), health, dowry or wedding expenses or receipts, government schemes, new business activity and migration for labour.

Eight in-depth FGDs were conducted in August $2014^{6}$ - three in Jeypore, two in Kolli Hills and three in Wayanad. FGDs were conducted in the local language of each location, and composed of approximately 12 individuals from a sub-sample of the households involved in the survey questionnaire, stratified by land ownership, ST status, and from households that had living representatives from three generations of household heads (see Appendix Table 2). The generations included the current or "young adult" generation (GEN3), the interim or "parent" generation (GEN2) and the elder or "grandparent" generation (GEN1). As in the survey, these questions were framed to reflect a time when the respondent was between 30-40 years old, which assisted in determining wellbeing change over time and allowed for crosschecking of results vertically within households and horizontally with peers of the same generation. A summary of the questions is found in Appendix Table 3.

Analysis of the FGD responses was conducted using a thematic approach. In the first phase, recordings and notes from the FGDs were reviewed and linked with facilitator observations from the meeting. In the second phase, each response ${ }^{7}$ provided by participants captured the discussant's gender, generation, research location and ST status. In the third phase, responses were reviewed for common themes, such as major events, optimistic or pessimistic impressions. Fourth, themes were finalized and identified. Three distinct categories were associated with wellbeing trajectories: optimistic, neutral and pessimistic. These categories each

\footnotetext{
${ }^{6}$ Preliminary FGDs were conducted in the research locations in August and September 2013. MSSRF APM staff in the research locations selected approximately 10 participants from the local villages that included local panchayat leaders and elders in the community. These FGDs were semi-formal with the purpose to inform the development of in-depth FGDs.

${ }^{7}$ An uninterrupted response from any individual in the FGD, not group consent or non-verbal communication techniques.
} 
represent the general opinion expressed by the respondent towards their wellbeing trajectory. Finally, these results were synthesized and interpreted for each category of interest (pooled, research site, ST and landed status). Representative quotes from each FGD response category were identified and recorded to provide examples of the sentiments. Significant events were also included in the trajectory of wellbeing analysis.

\section{Results}

\subsection{Standard of Living}

Survey respondents indicate that their wellbeing has been gradually improving over time (Figure 2). Forty-one per cent of GEN1 representatives felt they were at a low standard of living when they were between 30-40 years of age, compared to 22.3 per cent of GEN2 and 10.3 per cent of GEN3 respondents. There has been a decrease of low category households, and an increase of those living in medium and medium-high categories. Notably, very few households considered themselves in the high category in any time period. The medium low category is where much of the transition is occurring, as many households moved between low and mediumlow categories between GEN1 and GEN2. Between GEN2 and GEN3 most transition occurred to the higher wellbeing groups, hence the tapering off of those identifying as medium low in GEN3. These results support the literature that suggests most transition occurs from households in intermediate levels of wellbeing (Barrett and Carter 2013). 


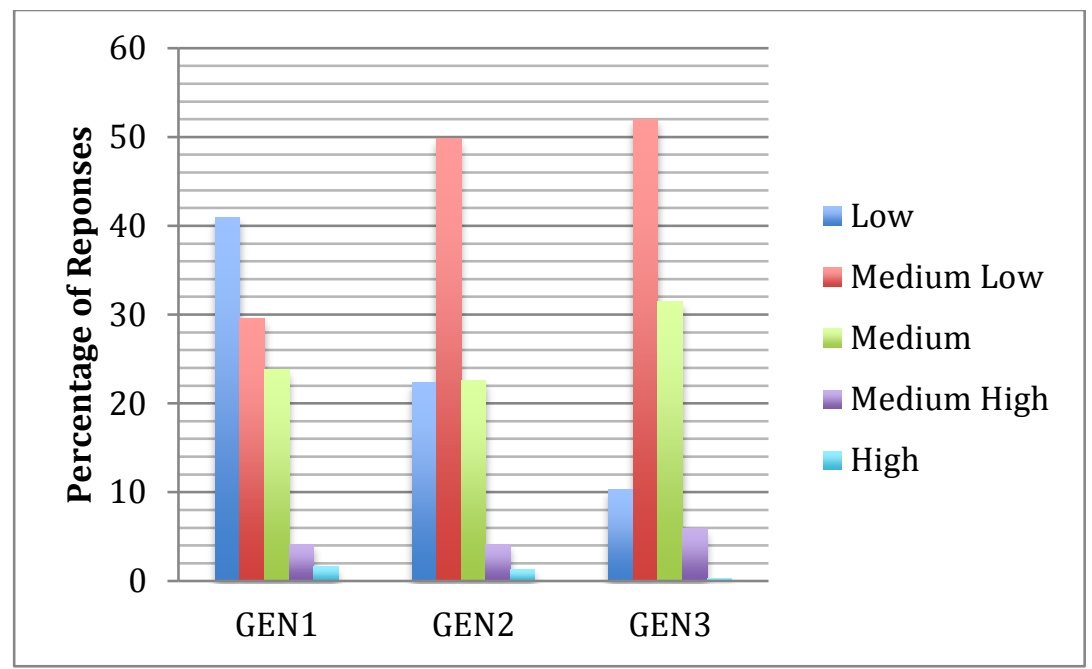

Figure 2. The perceived standard of living among surveyed household heads across all research locations when they were between 30-40 years of age.

\subsection{Wellbeing Trajectories}

The FGDs elaborated on this query by asking participants: has your status of wellbeing changed over the last twenty years? Pooling responses resulted in parallels with the survey data, where most participants (47 per cent) indicated a general sense of improvement, while only 29 per cent of responses suggested that things had gotten worse. The remaining 24 per cent of the responses were neutral; these respondents felt their wellbeing had remained constant over time. Overall trends associated with the pooled responses across all generations were: major increases in infrastructure provision (schools, roads, hospitals, etc.); changes in food and lifestyle - diets are increasingly less reliant on food produced locally and in the forests; marketing has become easier as trucks now come to the farm to pick up produce. Most participants also felt that education levels were increasing meaning greater prosperity for future generations. GEN1 participants spoke with greater optimism than the younger individuals - in particular those with young children. In every FGD a sentiment was expressed lamenting the urban migration of rural 
youth. The pooled and stratified responses are provided in Figure 3 below and will inform the more detailed and stratified analysis.

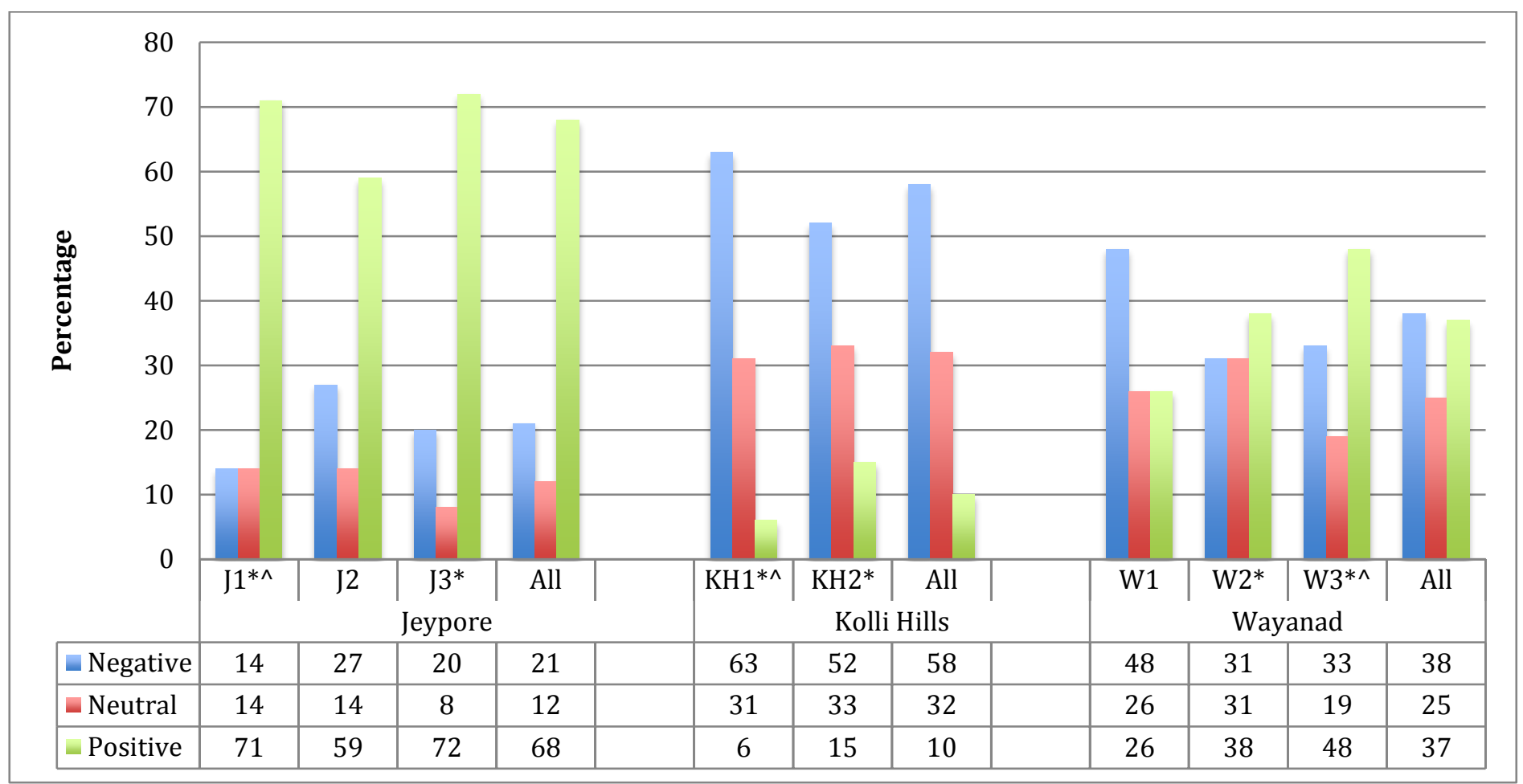

Figure 3. The perceived wellbeing of FGD participants in August 2014 from the three research sites individually and pooled; ^ indicates landless households and * ST households.

\subsubsection{Research Site Comparison}

A comparison of responses between the individual FGDs and a summary of pooled responses from each research location provide insight into site-specific perspectives. At the aggregate level, Jeypore has a much higher percentage of positive responses than the other locations; Kolli Hills tends to be more pessimistic, and Wayanad had no consensus position, with responses varying between positive, negative and neutral (Figure 3). Deeper insight into their responses is contained in the representative statements presented in Appendix Table 4. These responses indicate that new wage earning opportunities and crop prices were positive 
contributing factors, while government corruption that limited access to schemes were negative factors. Factors such as changing climatic conditions, long distances to market and alcoholism amongst men were major concerns, resulting in a majority of responses of a pessimistic or neutral perspective.

Exploring the individual FGDs responses within each site yields more insight into these aggregate trends. The Jeypore research site is located within Odisha, the state with the lowest human development index of the three locations. Therefore our expectation was that respondents would be on average more pessimistic regarding their wellbeing trajectories. However, respondents in all three FGDs were on average more positive about the future outlook than negative. Despite a higher human development index in Tamil Nadu, participants in the Kolli Hills FGDs were the most pessimistic. Kerala has the highest state level human development index in India (Government of India, 2013). An exception to the general optimistic outlook shown among most FGDs was the landless ST group in the Kolli Hills. Participants in this group felt that droughts in recent years have left them destitute and they are unable to think of a more positive future. Repeated reference to alcoholism amongst men, specifically in the Kolli Hills, was a common theme. However, the FGD responses from Wayanad did not reflect this statistic and yielded contrasting results (Appendix Table 4).

Overall, the information obtained from the FGDs presents a narrative of disparity within the state level wellbeing statistics. Jeypore households, although in a relatively poor state and area, have a relatively positive outlook. Kolli Hills households, situated in a relatively wealthy state but marginalized area, have a relatively pessimistic outlook. Finally, Wayanad households, although situated in a wealthy state and wealthy area, have perceptions on wellbeing that are ambiguous between positive, neutral and negative. 


\subsubsection{ST Membership}

Comparison of the perceptions between ST and non-ST households in the research area is of particular interest due to the marginalization of ST populations in India (Census of India, 2011; Haseena, 2015). As the populations in all the research locations are predominantly ST, six of the FGDs were composed of ST households and two were non-ST, representing the general population composition in these areas. Contrary to our expectations, pooling the responses from all ST and non-ST groups did not yield significant difference between the ST and non-ST participants. Overall, 42 per cent of the ST groups were positive while 43 per cent of the non-ST groups were positive (Figure 3). Negative and neutral responses were also very similar in terms of response percentages. Responses from the two non-ST focus groups again show a distinct difference between the two groups; J2 has a relatively positive outlook of 59 per cent, while W1 is much lower at 26 per cent (Figure 3).

Representative statements from FGDs based upon ST status are provided in Appendix Table 5. Common responses for the wellbeing perspectives include: wage increases, caste certificates and education. Common response themes from the non-ST FGDs tend to focus on technology improvement, government schemes, commodity prices and climate variation. Our result indicates that despite significant difference in national income statistics on the disparity between ST and non-ST households (Ministry of Tribal Affairs, 2015), the perception of wellbeing trajectories between these groups in our research locations is relatively similar.

\subsubsection{Land Ownership}

A comparison of the FGD responses based upon land ownership provides insight into the influence of land asset holdings on the wellbeing expectations of households. Our results indicate that neither landed nor landless households had a consensus option on their wellbeing, with 
responses relatively balanced three ways between positive, negative and neutral positions. The representatives statements presented in Appendix Table 6 provide an impression of the perceptions of each group. Dominant responses for the reasons for their responses included labour migration opportunities, price of commodities and changing climatic conditions indicating that landless households are highly dependent upon agricultural work for their livelihoods, even if they do not own the land themselves.

\subsection{Significant Events}

The importance of significant events on household wellbeing is well documented (Alam \& Mahal, 2014; Mazumdar et al., 2014). The survey instrument included options for several of the major significant events described in the literature: natural disasters, livestock inheritance, land inheritance, crop production changes, health, dowry or wedding expenses, government programs, new business activity, migration for labour, and "did not experience". Some of these events can have both positive and negative implications on households: asset inheritance is good but can there may not be capacity to manage it; crop production changes can lead to greater yields but different pests; weddings can bring wealth but also demand financial output; new business opportunities can lead to greater wealth, but also more risk; and migration for labour can bring income but separate family units. The survey responses shown in Table 1 show these opposing impacts, and therefore benefit from the FGD responses to interpret.

\begin{tabular}{|c|c|c|c|c|c|c|}
\hline \multirow[t]{2}{*}{ Significant Event } & \multicolumn{2}{|c|}{$\begin{array}{c}\text { GEN1 } \\
(\mathrm{N}=125)\end{array}$} & \multicolumn{2}{|c|}{$\begin{array}{c}\text { GEN2 } \\
(\mathrm{N}=469)\end{array}$} & \multicolumn{2}{|c|}{$\begin{array}{c}\text { GEN3 } \\
(\mathrm{N}=302) \\
\end{array}$} \\
\hline & POS & NEG & POS & NEG & POS & NEG \\
\hline 0. Did not & 78.4 & 72.0 & 66.5 & 74.4 & 59.3 & 67.2 \\
\hline
\end{tabular}




\begin{tabular}{|c|c|c|c|c|c|c|c|}
\hline & experience & & & & & & \\
\hline \multirow[t]{2}{*}{ Negative } & $\begin{array}{l}\text { 1. Natural } \\
\text { Disaster }\end{array}$ & 0.0 & 10.4 & 0.0 & 11.3 & 0.0 & 5.6 \\
\hline & 2. Health & 0.0 & 8.0 & 0.0 & 9.8 & 0.0 & 17.6 \\
\hline \multirow[t]{7}{*}{$\begin{array}{l}\text { Positive } \\
\text { or } \\
\text { Mixed } \\
\end{array}$} & $\begin{array}{l}\text { 3. Crop } \\
\text { Production } \\
\text { Change }\end{array}$ & 2.4 & 0.8 & 11.1 & 1.1 & 9.3 & 1.0 \\
\hline & $\begin{array}{l}\text { 4. Livestock } \\
\text { Inheritance }\end{array}$ & 0.0 & 0.0 & 5.3 & 0.9 & 0.7 & 1.7 \\
\hline & $\begin{array}{l}\text { 5. Land } \\
\text { Inheritance }\end{array}$ & 2.4 & 2.4 & 9.0 & 1.7 & 3.0 & 3.3 \\
\hline & $\begin{array}{l}\text { 6. Government } \\
\text { Schemes }\end{array}$ & 1.6 & 0.0 & 2.6 & 0.2 & 12.9 & 0.0 \\
\hline & 7. New Business & 3.2 & 2.4 & 2.8 & 0.0 & 10.3 & 0.0 \\
\hline & $\begin{array}{l}\text { 8. Migration for } \\
\text { Labour }\end{array}$ & 11.2 & 4.0 & 0.9 & 0.0 & 1.0 & 0.3 \\
\hline & 9. Weddings & 0.8 & 0.0 & 1.9 & 0.6 & 3.6 & 3.3 \\
\hline
\end{tabular}

The FGDs delved further into these responses arising from the survey data. We asked respondents to identify the significant positive or negative events they have experienced in the last 20 years. Of the 62 responses to this question, only 11 per cent of these were positive and 53 per cent were negative. ${ }^{8}$ Statements from respondents about these events are provided in the Appendix Table 6. Common responses include: migration, inheritance of land, infrastructure improvements (such as roads and marketplaces), and new farming technology and government assistance. Other significant events were not as highly represented or as consistent among respondents. Shocks such as weddings, new business opportunities and migration were deemed by some households to be positive and by others to be negative. This outcome also is similar to articles that explored the gendered and generational changes for dowries (Anderson, 2007; Quisumbing, 2011) and migration (de Brauw et al., 2013).

\footnotetext{
${ }^{8}$ The remaining 35 per cent of responses was neutral.
} 


\subsubsection{Positive Events}

Among the surveyed participants, approximately two-thirds of all respondents did not experience a positive event that significantly influenced their wellbeing trajectory. For these households the long and steady climb out of poverty was not influenced by external shocks. For those households that did benefit from a positive significant event, the most important events were migration for labour, asset inheritance (livestock and land) changes in crop production, new businesses and government schemes (Table 8).

Generational differences were also evident in the most important positive events. In GEN1, the most important positive event was the opportunity to migrate for work -11.2 per cent of individuals felt this has significantly positively impacted their lives. GEN2 household heads considered new crop production techniques and land inheritance the two most important events,

impacting 11.1 and 9 per cent of respondents, respectively. Livestock inheritance was also important for 5.3 per cent of respondents. The most important positive event for GEN3 was government schemes -12.9 per cent of individuals attribute their wellbeing advance to this factor. New business opportunities and changes in crop production were also important to GEN3 respondents (Table 1).

\subsubsection{Negative Events}

A relatively high percentage of respondents also did not experience any negative event (Table 1). Among those that did, however, natural disasters such as drought and flooding impacted 10.4, 11.3 and 5.7 per cent of households in GEN1, GEN2 and GEN3, respectively. Health problems impacted 8, 9.8 and 17.2 per cent of households across the same generations. This result is similar to other studies that found that climate and health impacts were a major 
depleting factor upon all ages of household members (Alam \& Mahal, 2014; Mazumdar et al., 2014).

Negative events often receive more attention in FGDs, as participants are able to share their concerns and receive a level of support from the group experience. This pattern was also evident in the survey data: 33 (53 percent) of the responses regarding significant event recollection were negative. Some of the examples of negative events described over the last twenty years are presented in Table 9 below. Examples of negative events experienced include: drought 20 years ago and currently in the Kolli Hills; death of a son in a family in Wayanad; personal injury and sickness and the loss of a home due to fire. When asked about falling back into poverty, no families specifically mentioned this occurring; while household wellbeing trajectories seemed to plateau and even dip at times, they did not perceive themselves to be in trapped in a condition of chronic poverty.

The ST respondents in Wayanad identified and discussed their forced removal from the forest several decades ago as a serious negative event (K. Kumar, Singh, \& Kerr, 2015). While only the GEN1 participant remembered this event clearly, the level of trauma this experience created in these individuals, households and communities was very high (Steur, 2009).

\subsection{Summary}

Our stratification of the FGDs samples provides slightly different results across individual research locations, but no consistent differences between ST or land disaggregation. Jeypore is very positive, Kolli Hills is predominantly negative and Wayanad is divided between the three categories. Land asset ownership was ambiguous, as optimism and pessimism were fairly equally represented by both landed and landless households. ST membership again showed mixed results: 
non-ST households were fairly neutral and ST households were similarly neutral. A comparison of the different responses between FGDs is provided in Table 2.

\begin{tabular}{|l|l|l|l|}
\hline \multicolumn{2}{|l|}{ Table 2. Comparison of FGD level perceptions of wellbeing across location, landed and ST status. } \\
\hline & Jeypore & Kolli Hills & Wayanad \\
\hline Landed ST & & & \\
\hline Landless ST & & No FGD & \\
\hline Landed Non-ST & & \\
\hline Green = positive; Yellow = neutral; Red = negative; Grey = ambiguous
\end{tabular}

\section{Discussion and Conclusion}

Contrary to the national and state level statistics on poverty and wellbeing in rural and remote regions of India, our results indicate suggest generally positive perspectives about their wellbeing trajectories over time and between generations. This result contrasts with other quantitative research that has found a large poverty incidence gap between ST and non-ST households (Census of India, 2011; Gang, Sen, \& Yun, 2008; Kirubakaran, 2013). This difference may be explained by the qualitative discussions used in this study versus the more quantitative measures poverty (income or expenditure) employed elsewhere. Therefore while ST households may exist with very low levels of income, they do not perceive their wellbeing or future trajectory to be negative. It also contrasts with land reform and policies across India, where landlessness is viewed as a serious limitation to development (Manjunatha, Anik, Speelman, \& Nuppenau, 2013; Rawal, 2008, 2013). This study does not contradict the importance of land reform to address landlessness as a social issue, but seems to indicate that landlessness is not a major limitation to wellbeing advance in these locations. 
The greatest difference found was between research locations, indicating that socioeconomic conditions specific to each research site are predominant over household characteristics such as land ownership and ST status. For example, the debilitating social impact of alcoholism was highlighted in the Kolli Hills. While alcoholism has been identified as a public health issue in other parts of India (R. K. Kumar \& Tiwari, 2016; World Health Organization, 2011b) and is particularly prevalent among ST communities (R. K. Kumar \& Tiwari, 2016), no published reference exists on this issue in the Kolli Hills. There are both economic and moral incentives to address this issue, as it decreases productivity, impacts social dimensions and has a disproportionately negative impact on women (Barman, Bhattacharya, Lyngdoh, \& Jamil, 2015; World Health Organization, 2011a). More specific research on this issue in all these locations, but Kolli Hills specifically, should be conducted.

Differing intergenerational perspectives nature of poverty dynamics was also evident. Elderly participants were generally optimistic, feeling that a major contributing factor to their wellbeing advance was migration for labour, with less emphasis on government schemes. As fewer government schemes and infrastructure was available to them during their years as active household heads (Government of India, 2016; Jha, Bhattacharyya, Gaiha, \& Shankar, 2009), this is unsurprising, but it does highlight a shift in expectations across the nation. Reliance on government schemes has become a mainstay of the current generations. Late middle-aged respondents were only marginally less optimistic than the previous generation, and attributed much of their positive advancement to the inheritance of land and adoption of new crop varieties. This supports the importance of intergenerational asset transfer (Bennett, 2013; Hatlebakk, 2014), but also highlights how division of land in consecutive generations often results in smaller 
individual land areas and family disputes (Deininger, Goyal, \& Nagarajan, 2013; Manjunatha et al., 2013).

While our findings are at one level positive regarding development outcomes, it should not be interpreted as a reason to continue focused strategies for poverty alleviation, as poverty is still persistent in these locations. Ongoing research and government support is necessary in these communities. We suggest that further insights into the perspectives on wellbeing in these Ghat regions of India should be explored to ensure that poverty alleviation strategies are aligned with both the perceived wellbeing and economic realities of the local households. 


\section{REFERENCES}

Alam, K., \& Mahal, A. (2014). Economic impacts of health shocks on households in low and middle income countries: a review of the literature. Globalization and Health, 10(1), 21. http://doi.org/10.1186/1744-8603-10-21

Anderson, S. (2007). The Economics of Dowry and Brideprice. Journal of Economic Perspectives, 21(4), 151-174.

Aubron, C., Lehoux, H., \& Lucas, C. (2015). Poverty and inequality in rural India . Reflections based on two agrarian system analyses in the state of Gujarat. EchoGéo, (32).

Barman, B., Bhattacharya, P. K., Lyngdoh, M., \& Jamil, M. (2015). Alcoholism - A health burden: A study from north eastern India. Indian Journal of Medical Specialities, 6(2), 5558. http://doi.org/10.1016/j.injms.2015.02.008

Barrett, C. B., \& Carter, M. R. (2013). The Economics of Poverty Traps and Persistent Poverty: Empirical and Policy Implications. Journal of Development Studies, 49(7), 976-990. http://doi.org/10.1080/00220388.2013.785527

Bawa, K. S., Joseph, G., \& Setty, S. (2007). Poverty, biodiversity and institutions in forestagriculture ecotones in the Western Ghats and Eastern Himalaya ranges of India. Agriculture, Ecosystems \& Environment, 121(3), 287-295. http://doi.org/10.1016/j.agee.2006.12.023

Bennett, F. (2013). Researching Within-Household Distribution: Overview, Developments, Debates, and Methodological Challenges. Journal of Marriage and Family, 75(3), 582-597. http://doi.org/10.1111/jomf.12020

Bird, K. (2010). Using life history research as part of a mixed methods strategy to explore resilience in conflict and post- conflict settings.

Census of India. (2011). Demographic Status of Scheduled Tribe Population of India.

de Brauw, A., Mueller, V., \& Woldehanna, T. (2013). Does Internal Migration Improve Overall Well-Being in Ethiopia?

de Nicola, F., \& Gine, X. (2012). How Accurate Are Recall Data? Evidence from Coastal India. Retrieved April 7, 2016, from http://www.alnap.org/resource/8104.aspx

Deininger, K., Goyal, A., \& Nagarajan, H. (2013). Women's Inheritance Rights and Intergenerational Transmission of Resources in India. Journal of Human Resources, 48(1), 114-141. http://doi.org/10.3368/jhr.48.1.114

Deshingkar, P. (2010). Migration, remote rural areas and chronic poverty in India (No. 323).

Dillon, A., \& Quiñones, E. J. (2010). Gender differentiated asset dynamics in Northern Nigeria.

Dutta, S. (2012). Asset Poverty in Rural India at World Economics. Retrieved from http://www.worldeconomics.com/Papers/Asset Poverty in Rural India_c70c32f5-061d4582-bd49-10dd63ae7463.paper?PaperID=C70C32F5-061D-4582-BD49-10DD63AE7463

FAO, IFAD, \& WFP. (2014). The State of Food Insecurity in the World: Strengthening the 
enabling environment for food security and nutrition.

Fisher, B., \& Christopher, T. (2007). Poverty and biodiversity: Measuring the overlap of human poverty and the biodiversity hotspots. Ecological Economics, 62(1), 93-101. http://doi.org/10.1016/j.ecolecon.2006.05.020

Gang, I. N., Sen, K., \& Yun, M.-S. (2008). Poverty in Rural India: Caste and Tribe. Review of Income and Wealth, 54(1), 50-70. http://doi.org/10.1111/j.1475-4991.2007.00259.x

Government of India. (2013). Census of India 2011 Highlights.

Government of India. (2016). Schemes National Portal of India. Retrieved April 9, 2016, from https://india.gov.in/my-government/schemes

Haseena, V. A. (2015). Poverty and livelihood problems among the scheduled tribes in Kerala-A Study on Attappady. Journal of Poverty, Investment and Development.

Hatlebakk, M. (2014). Poverty Dynamics in Rural Orissa: Transitions in Assets and Occupations over Generations. The Journal of Development Studies, 50(6), 877-893. http://doi.org/10.1080/00220388.2014.887691

Imai, K. S., Gaiha, R., \& Thapa, G. (2015). Does non-farm sector employment reduce rural poverty and vulnerability? Evidence from Vietnam and India. Journal of Asian Economics, 36, 47-61. http://doi.org/10.1016/j.asieco.2015.01.001

Jackson, L. E., Pascual, U., \& Hodgkin, T. (2007). Utilizing and conserving agrobiodiversity in agricultural landscapes. Agriculture, Ecosystems \& Environment, 121(3), 196-210. http://doi.org/10.1016/j.agee.2006.12.017

Jacoby, H. G. (2016). Food Prices, Wages, And Welfare In Rural India. Economic Inquiry, 54(1), 159-176. http://doi.org/10.1111/ecin.12237

Jha, R., Bhattacharyya, S., Gaiha, R., \& Shankar, S. (2009). "Capture” of anti-poverty programs: An analysis of the National Rural Employment Guarantee Program in India. Journal of Asian Economics, 20(4), 456-464. http://doi.org/10.1016/j.asieco.2009.03.003

Kadur, S., \& Bawa, K. S. (2005). Sahyadris, India's Western Ghats, a vanishing heritage. ATREE.

Kirubakaran, G. J. (2013). Socio Economic Status of Tribal's in Kollihills of Tamilnadu and their Community Participation. Indian Journal of Applied Research, III(XII), 181-184.

Kjellsson, G., Clarke, P., \& Gerdtham, U.-G. (2014). Forgetting to remember or remembering to forget: A study of the recall period length in health care survey questions. Journal of Health Economics, 35, 34-46. http://doi.org/10.1016/j.jhealeco.2014.01.007

Kreft, S., Eckstein, D., Junghans, L., Kerestan, C., \& Hagen, U. (2015). Global Climate Risk Index 2015. Who Suffers Most From Extreme Weather Events? Weather-related Loss Events in 2013 and 1994 to 2013.

Krishna, A. (2004). Escaping Poverty and Becoming Poor: Who Gains, Who Loses, and Why? World Development, 32(1), 121-136. http://doi.org/10.1016/j.worlddev.2003.08.002

Krishna, A. (2006). Pathways out of and into poverty in 36 villages of Andhra Pradesh, India. World Development, 34(2), 271-288. http://doi.org/10.1016/j.worlddev.2005.08.003 
Kumar, K., Singh, N. M., \& Kerr, J. M. (2015). Decentralisation and democratic forest reforms in India: Moving to a rights-based approach. Forest Policy and Economics, 51, 1-8. http://doi.org/10.1016/j.forpol.2014.09.018

Kumar, R. K., \& Tiwari, R. (2016). A cross sectional study of alcohol consumption among tribals and non-tribals adults of Narayanganj block in Mandla district of Madhya Pradesh, India. International Journal of Community Medicine and Public Health, 3(4), 791-795.

Manjunatha, A. V., Anik, A. R., Speelman, S., \& Nuppenau, E. A. (2013). Impact of land fragmentation, farm size, land ownership and crop diversity on profit and efficiency of irrigated farms in India. Land Use Policy, 31, 397-405. http://doi.org/10.1016/j.landusepol.2012.08.005

Mazumdar, S., Mazumdar, P. G., Kanjilal, B., \& Singh, P. K. (2014). Multiple shocks, coping and welfare consequences: natural disasters and health shocks in the Indian Sundarbans. PloS One, 9(8), e105427. http://doi.org/10.1371/journal.pone.0105427

Meagher, K. (2010). The empowerment trap: gender, poverty and the informal economy in subSaharan Africa. Retrieved April 10, 2016, from http://wiego.org/sites/wiego.org/files/publications/files/Meagher_Gender.Empowerment.Tra p_.pdf

Ministry of Tribal Affairs. (2015). Annual Report 2014-15.

Moore, K. (2001). Frameworks for Understanding the Inter-Generational Transmission of Poverty and Well-Being in Developing Countries. SSRN Electronic Journal. http://doi.org/10.2139/ssrn.1754527

Narayan, D., \& Petesch, P. (2002). Voices of the Poor: From Many Lands. Oxford University Press and the World Bank.

Narayan, D., Sen, B., \& Hull, K. (2010). Moving Out of Poverty in India: An Overview. The Promise of Empowerment and Democracy in India.

Novotný, J., Kubelková, J., \& Joseph, V. (2013). A multi-dimensional analysis of the impacts of the Mahatma Gandhi National Rural Employment Guarantee Scheme: A tale from Tamil Nadu. Singapore Journal of Tropical Geography, 34(3), 322-341. http://doi.org/10.1111/sjtg.12037

Quisumbing, A. R. (2011). Do Men and Women Accumulate Assets in Different Ways? Evidence from Rural Bangladesh (No. 1096).

Rawal, V. (2008). Ownership Holdings of Land in Rural India: Putting the Record Straight. Economic and Political Weekly, 43(10), 43-47.

Rawal, V. (2013). Changes in the Distribution of Operational Landholdings in Rural India: A Study of National Sample Survey Data. Journal, 3(2), 73-104.

Reddy, S. C., Jha, C. S., \& Dadhwal, V. K. (2014). Spatial dynamics of deforestation and forest fragmentation in Eastern Ghats, India. In ISPRS - International Archives of the Photogrammetry, Remote Sensing and Spatial Information Sciences (Vol. XL-8, pp. 637644). http://doi.org/10.5194/isprsarchives-XL-8-637-2014

Ryan, T. P. (2013). Sample Size Determination and Power. John Wiley \& Sons, Inc. 
Sahoo, L. K. (2011). Socio-Economic Profile of Tribal Populations in Mayurbhanj and Keonjhar Districts. Orissa Review, 63-68.

Smith- Lovin, L. (1987). The affective control of events within settings. Journal of Mathematical Sociology, 13(1-2), 71-101.

Steur, L. (2009). Adivasi Mobilisation: "Identity" versus "Class" after the Kerala Model of Development? Journal of South Asian Development, 4(1), 25-44. http://doi.org/10.1177/097317410900400103

Sumner, A. (2012). Where Do The Poor Live? World Development, 40(5), 865-877. http://doi.org/10.1016/j.worlddev.2011.09.007

Suryanarayana, M. H., Agrawal, A., \& Prabhu, K. S. (2011). Inequality-adjusted Human Development Index for India's States.

Weber, M. (2009). From Max Weber: Essays in Sociology. (H. H. Gerth \& C. W. Mills, Eds.).

White, S. C. (2010). Analysing wellbeing: a framework for development practice. Development in Practice, 20(2), 158-172.

World Bank. (2015). Global Monitoring Report 2015/2016: Development Goals in an Era of Demographic Change. The World Bank.

World Bank. (2016). India's Poverty Profile: Snapshot 2012. Retrieved June 8, 2017, from http://www.worldbank.org/en/news/infographic/2016/05/27/india-s-poverty-profile

World Health Organization. (2011a). Global status report on alcohol and health. World Health Organization.

World Health Organization. (2011b). India Alcohol Consumption: Levels and Patterns. 